\title{
Buenos Aires, espacio público Y LITERATURA
}

Buenos Aires, Public Space and Literature

\author{
Innés Moisset \\ ines.moisset@gmail.com \\ Consejo Nacional de Investigaciones Científicas y Técnicas \\ (CONICET), Argentina \\ Ismael Eyras \\ ieyras@yahoo.com.ar \\ Universidad de Buenos Aires
}

RESUMEN: El artículo propone la mirada del literato como herramienta para la comprensión del espacio público. En este ensayo en particular se aplicará al caso específico de Buenos Aires durante los años 20, a partir de la confluencia de personajes notables: cuatro escritores (Arlt, Storni, Borges y Marechal) y un arquitecto (Bereterbide) que nacen sobre el cambio de siglo. Son cinco miradas sobre la gran transformación que atravesó la ciudad en aquel entonces y que aportan a la comprensión del fenómeno.

Palabras clave: literatura, espacio urbano, Roberto Arlt, Alfonsina Storni, Jorge Luis Borges, Leopoldo Marechal, Fermín Bereterbide.

ABSTRACT: The article proposes the writer eye as a tool for understanding the public space. In this particular essay it shall apply to the specific case of Buenos Aires during the 20s, from the confluence of notables: four writers (Arlt, Storni, Borges and Marechal) and an architect (Bereterbide) born on the turn of the century. There are five perspectives on the great transformation that the city crossed at the time and that contribute to the understanding of the phenomenon.

KeYwords: literature, Public Space, Roberto Arlt, Alfonsina Storni, Jorge Luis Borges, Leopoldo Marechal, Fermín Bereterbide. 
RESUM: L'article proposa la mirada del literat com a eina per a la comprensió de l'espai públic. En aquest assaig en particular s'aplicarà al cas específic de Buenos Aires durant els anys 20, a partir de la confluència de personatges notables: quatre escriptors (Arlt, Storni, Borges i Marechal) i un arquitecte (Bereterbide) que neixen al voltant del canvi de segle. Són cinc mirades sobre la gran transformació que va travessar la ciutat aleshores i que aporten a la comprensió del fenomen.

Paraules clau: literatura, espai urbà, Roberto Arlt, Alfonsina Storni, Jorge Luis Borges, Leopoldo Marechal, Fermín Bereterbide.

\section{Introducción}

sí como los arquitectos y urbanistas tienen como objeto de estudio la
forma arquitectónica y la forma urbana, también otras artes - pintura, música y literatura - hacen referencia o utilizan el espacio y la forma arquitectónica y urbana en sus obras. En el caso específico de la literatura, las ciudades y los diferentes espacios construidos muchas veces forman parte importante o protagónica de la obra literaria.

¿Cuáles son los vínculos y las tensiones entre lo literario y lo espacial? Para resolver este interrogante pensamos en desarrollar una búsqueda a través de un formato alternativo al de un documento académico. En 2014 creamos un blog denominado Sembrar en el desierto (Eyras \& Moisset, 2014) desde donde intentamos realizar una reflexión abierta a un público más amplio: aquél que accede desde las redes sociales y que interactúa con nosotros. Y también planteamos que la reflexión es abierta en el sentido de que no hay un momento de cierre o conclusión, ya que se suman textos e imágenes a medida que éstos siguen apareciendo (o surgiendo de la biblioteca).

Los contenidos del blog habitan en un espacio intermedio. Estos espacios se producen en los bordes de las disciplinas, donde encontramos áreas ambiguas, solapadas, entretejidas. Tal es el caso de las interrelaciones entre literatura, arquitectura y urbanismo. 
Si bien Borges se sorprende de que a los arquitectos les interese la literatura (Grau, 1989), la discusión teórica sobre los vínculos entre arquitectura, ciudad y literatura, no es nueva. ${ }^{1}$ Reconocidos teóricos han desarrollado profundas reflexiones sobre ellos, de las cuales planteamos aquí un breve repaso. Marina Waisman, en un Summarios dedicado a la literatura, señala que una lectura «otra» de la ciudad, la lectura del literato y del poeta, puede iluminar con nuevas claridades nuestra propia lectura.

Parece necesario $[\ldots]$ mirar nuestros habituales objetos de estudio a través de instrumentos ajenos explicados con sistemas diferentes [...] Si esa mirada y esos instrumentos se alejan de lo científico y analítico [...] tanto más probable será que podamos, al menos por el momento, dejar de lado nuestro propio aparato de intelección y tener una visión diferente que enriquezca la habitual o la modifique y que nos prevenga del peligro de la alienación causada por el encierro en nuestro propio círculo. (Waisman, 1985, p. 2)

Roberto Doberti, en su libro Espacialidades destaca la relación entre el hablar y el habitar: «la Escritura y la Ciudad [...] instauraciones que parecen llamarse una a la otra, o tal vez necesitarse, funcionando otra vez como concatenaciones, que se anudan y se activan mutuamente» (Doberti, 2008, p. 35). También se refiere a los vínculos entre proyecto y novela como prácticas y productos decisivos de la Modernidad.

La relación entre escritura y habitar también había sido observada por Jacques Derrida: «La oposición entre tiempo y espacio, entre el tiempo del discurso y el espacio de un templo o el de una casa carece de sentido. Se vive en la escritura... Escribir es un modo de habitar» (Meyer, 1988, p. 12).

Gaston Bachelard desarrolla estas ideas en su valioso libro La poética del espacio: «Hay que amar el espacio para describirlo tan minuciosamente como si hubiera moléculas del mundo» (Bachelard, 1965, p. 144).

El blog Sembrar en el desierto parte de la idea de acompañar textos literarios seleccionados con unas pocas imágenes ilustrativas asociadas libremente

1. Aun así, sabiendo que los arquitectos no leen, decidimos iniciar las publicaciones... con una actitud terca, si se quiere de «cabezas duras», obrando a pesar de, en contra de, a contramano de... Un trabajo infructuoso, realizado sin sentido ni lógica. La frase de Simón Bolívar, que decepcionado ante la división de la Gran Colombia dijo: «He arado en el mar, he sembrado en el desierto» nos resultó apropiada y de ésta surge el nombre del blog. 
(en términos de asociación libre psicoanalítica) con el escrito. Por el contrario, en otras ocasiones solemos encontrar imágenes interesantes que pueden enriquecer el blog y a partir de éstas se eligen textos que pueden adecuarse a su clima o maridar con ellas. Una imagen vale mil palabras y a su vez una sola palabra remite a mil imágenes. No se trata aquí de ilustrar un texto ya que las imágenes no son descriptivas ni están subordinadas al texto, sino que tienen el mismo peso.

Cada nueva entrada propuesta implica revisar y expandir nuestro pensamiento sobre las múltiples relaciones entre el espacio narrado y el espacio vivido o construido; entre la palabra escrita y la imagen. Porque las ligazones entre espacio relatado y espacio construido son múltiples, complejas, transversales. Sesgadas, conflictivas y hasta promiscuas.

Esta relación diversa entre literatura e imágenes que experimentamos en el blog fue de alguna manera inspirada en diversos proyectos conjuntos entre fotógrafos y escritores, libros ilustrados o álbumes, de los cuales existen exquisitos ejemplos locales: Buenos Aires, mi ciudad (Makarius, 1963), Buenos Aires Buenos Aires (D'amico, Facio \& Cortazar, 1968), y Letra e imagen de Buenos Aires (Sessa \& Mujica Lainez, 1977). También, desde nuestra época de estudiantes, textos literarios han inspirado trabajos de exploración morfológica o proyectual, como las Ciudades Invisibles de Italo Calvino (2015).

Fuimos descubriendo los múltiples modos de asociar estos textos e imágenes y planteando el proyecto como algo lúdico, como un juego casi privado, en el cual estas asociaciones, lógicamente, nunca son explicitadas o comentadas para fomentar la participación o interpretación de cada lector.

El concepto de imaginarios o representaciones del territorio, la urbe, la arquitectura, el paisaje, es también desarrollado por Mario Sabugo (2013), quien pone especialmente mayor énfasis en la poesía del tango. Existen libros donde se intenta la comprensión de la ciudad utilizando a la literatura como herramienta, como Walter Benjamin (2005) que mira a París a través de los textos de Baudelaire. Y también hay finalmente libros emblemáticos que estudian con profundidad la relación entre la obra de un escritor y el espacio, la arquitectura y la ciudad. Tal es el caso de Borges y la arquitectura de Cristina Grau (1989). 
Los escritores son a su vez conscientes de esta retroalimentación entre el espacio físico y la acción de sus personajes. Así lo plantea magistralmente Lawrence Durrell en El cuarteto de Alejandría: «He venido a reconstruir piedra por piedra esa ciudad en mi mente» (Durrell, 2003, p. 6).

Lo que nació como un juego y una exploración intuitiva nos permitió acercarnos a la comprensión de realidades urbanas desde una nueva perspectiva. Tal es el caso de lo que ocurría en la ciudad de Buenos Aires entre los años 20 y 30. Existe una vanguardia literaria de alto nivel que se produce en un contexto de un gran dinamismo de la sociedad y de fuertes cambios en el entorno construido. Encontramos aquí relaciones de ida y vuelta entre estos sistemas: el espacio público emergente y el espacio relatado.

\section{La calle en los escritores porteños}

A partir de lo publicado seleccionamos cuatro escritores del siglo xx que describen las calles de la cambiante Buenos Aires. Son los jóvenes Roberto Arlt (1900-1942), Alfonsina Storni (1892-1938), Leopoldo Marechal (19001970) y Jorge Luis Borges (1899-1986). Los cuatro escritores nacieron con pocos años de diferencia y los textos también fueron escritos casi simultáneamente.

Los años 20 fueron un período de grandes transformaciones de la ciudad, designada capital de Argentina en 1880. Buenos Aires muta con la llegada masiva de los inmigrantes europeos (principalmente españoles e italianos). En 1914 era la duodécima ciudad más grande del planeta con más de un millón y medio de habitantes. Los recién llegados se localizan en condiciones de gran precariedad, en conventillos y villas. Dos operaciones fomentan la expansión de la ciudad: se extiende el tranvía y se comienzan a vender los lotes en cuotas. En 1925 se presenta el «Proyecto orgánico para la organización del municipio» bajo la intendencia de Noel. En esta época se hacen las primeras viviendas subsidiadas por el Estado y se promocionan de las sociedades de fomento.

Es también una época de enormes cambios en la infraestructura urbana, como la construcción el tren subterráneo, primero en América Latina y uno 
de los primeros del mundo. Corresponden a este período también grandes obras de ingeniería urbana y de transporte como la red de agua potable y cloacas y las grandes terminales ferroviarias de Retiro y Constitución. El país atravesaba un período de gran prosperidad económica que se refleja en la construcción de grandes hitos en la ciudad de Buenos Aires, públicos como el Teatro Colón y el Congreso de la Nación, o privados, como el Palacio Barolo, la Galería Güemes o el edificio de la confitería Del Molino, aportando monumentalidad y cierta modernidad a la europea a la nueva capital.

La ciudad de origen español, configurada en damero, comienza a expandirse y avanza sobre el territorio. El suburbio y los arrabales se transforman en protagonistas de la literatura. La calle es centro de atención de los escritores, tanto sus configuraciones físicas como los personajes que la habitan. No se entiende el espacio urbano sin los habitantes y sus costumbres. Estos cuatro escritores nos señalan la transformación de la Gran Aldea en la Ciudad Capital, construyendo un momento mítico. Pero también la nostalgia acompaña las imágenes plasmadas. La calle aparece en primer plano para la comprensión del espacio público.

\subsection{Aguafuertes porteñas, Roberto Arlt}

Arlt, hijo de inmigrantes, es inmune a los estereotipos de la escritura tradicional y más aún a los que provienen del extranjero. Al mismo tiempo que describe una ciudad nueva lo hace desde un nuevo lenguaje donde incorpora lo cotidiano a construcciones lingüísticas de vanguardia. Lo hace a conciencia intentando dinamitar el edificio literario de la época. Es consciente de que necesita nuevas palabras para los nuevos espacios urbanos (Goloboff, 2002).

Roberto Arlt escribe las Aguafuertes porteñas entre 1928 y 1933, una serie de ensayos periodísticos que cuestionan el progreso de la ciudad con tono irónico. La reflexión no proviene desde la teoría sino desde el recorrer las calles para comprender lo que está ocurriendo y donde su mirada aguda devela situaciones. Es la técnica del flâneur, utilizada por los escritores parisinos del siglo XIX. Aquí, al igual que en la Buenos Aires de principios del siglo $\mathrm{XX}$, las grandes transformaciones urbanas, en este caso las realizadas por el Barón de Haussmann, exigen reconectar al escritor con el espacio. La deriva 
por la ciudad sin rumbo permite capturar impresiones como un detective, diría Walter Benjamin. De hecho, Arlt trabajó también en la sección de crónicas policiales en un periódico. En el texto «El placer de vagabundear», que transcribimos casi completo, destaca la necesidad de buscar el conocimiento en el espacio público. Es observando sin prejuicios que se puede comprender este nuevo escenario que no es neutral sino que interactúa con los personajes que hasta el momento cierta literatura argentina negaba. También este escenario era negado por los arquitectos y teóricos argentinos, ocupados en estos momentos en la construcción de grandes obras. Así es como define Arlt su actividad de observador atento:

Comienzo por declarar que creo que para vagabundear se necesitan excepcionales condiciones de soñador.

Ya lo dijo el ilustre Macedonio Fernández: «No toda es vigilia la de los ojos abiertos».

Digo esto porque hay vagos, y vagos. [...] Ante todo, para vagar hay que estar por completo despojado de prejuicios y luego ser un poquitín escéptico, escéptico como esos perros que tienen la mirada de hambre y que cuando los llaman menean la cola, pero en vez de acercarse, se alejan, poniendo entre su cuerpo y la humanidad, una respetable distancia.

Claro está que nuestra ciudad no es de las más apropiadas para el atorrantismo sentimental, pero ¡qué se le va a hacer!

Para un ciego, de esos ciegos que tienen las orejas y los ojos bien abiertos inútilmente, nada hay para ver en Buenos Aires, pero, en cambio, iqué grandes, qué llenas de novedades están las calles de la ciudad para un soñador irónico y un poco despierto! ¡Cuántos dramas escondidos en las siniestras casas de departamentos! $[\ldots]$

La ciudad desaparece. Parece mentira, pero la ciudad desaparece para convertirse en un emporio infernal. Las tiendas, los letreros luminosos, las casas quintas, todas esas apariencias bonitas y regaladoras de los sentidos, se desvanecen para dejar flotando en el aire agriado las nervaduras del dolor universal. Y del espectador se ahuyenta el afán de viajar. Más aún: he llegado a la conclusión de que aquél que no encuentra todo el universo encerrado en las calles de su 
ciudad, no encontrará una calle original en ninguna de las ciudades del mundo. Y no las encontrará, porque el ciego en Buenos Aires es ciego en Madrid o Calcuta... ${ }^{2}$ (Arlt, 2001, p. 92)

Arlt destaca al grupo humano diverso que habita las calles: «Babel de todas las razas». La vida en el barrio, las casitas con jardín, los chicos jugando al fútbol, los muchachos en la esquina, el perro con pulgas, los vecinos conversando y las sillas en la vereda son datos que nos van mostrando a la calle como lugar de intercambio, de tradiciones, de espacio político y de vínculos solidarios entre los vecinos.

\subsection{Cuadrados y ángulos, Alfonsina Storni}

En este momento histórico eran pocas las mujeres que escribían y menos las que podían considerar la escritura como una fuente de sustento. En una sociedad organizada con roles marcados el mandato de la mujer era quedarse en la casa. Realizar observaciones por la ciudad, circular libremente era algo que no estaba considerado una actividad femenina como tampoco acceder a la educación y participar en política. Una mujer que escribía no era bien vista y muchas utilizaban seudónimos para firmar sus obras. Alfonsina Storni fue la única escritora de la época que intentó ganarse la vida con la escritura y participaba en igualdad de condiciones en los círculos literarios. Era una mujer independiente, madre soltera, una oveja negra como ella se definía (Szmetan, 1999, p. 116). El poema de amor era lo que correspondía a las mujeres escritoras, sin embargo, Storni se mete con la ciudad.

En este poema de 1918, Storni mira a una ciudad que se expande de una manera homogénea, una geometría que se repite de manera sistemática y que impacta en el interior de las personas. Es la ciudad de casitas cúbicas que Le Corbusier exalta como modernas en su visita a Buenos Aires. Este modelo de ciudad había sido elegido conscientemente por la administración pública. En 1910, Enrique Prins, señala en la publicación del Censo General de Población, Edificación, Comercio e Industrias de la ciudad de Buenos Aires que

2. El destacado es nuestro. 
«nada era más lógico ante aquel plano imperturbable que completar la obra existente con la expresión geométrica más simple y elemental: lo recto».

Para Storni, las fachadas de la calle configuran un espacio público anónimo y triste. Los habitantes son víctimas de este escenario y no son quienes lo producen. En esta época tampoco encontramos mujeres produciendo la ciudad. No es de extrañar que el paisaje se perciba como inhumano y ajeno. Nueve años después de la publicación de este poema termina sus estudios Filandia Pizzul (n. 1902), la primera argentina con título de arquitecta. Recién hacia los años 40 aparecen las urbanistas participando en oficinas públicas de la ciudad, como Itala Fulvia Villa (1913-1991). El espacio público aún no pertenece a las mujeres y ellas no sólo son recluidas en sus hogares y excluidas de los ámbitos públicos y la febril actividad de la ciudad industrial. Tampoco participan en su diseño. Esto es lo que manifiesta Storni con sus escritos:

Casas enfiladas, casas enfiladas, casas enfiladas.

Cuadrados, cuadrados, cuadrados.

Casas enfiladas.

Las gentes ya tienen el alma cuadrada,

ideas en fila

y ángulo en la espalda.

Yo misma he vertido ayer una lágrima,

Dios mío, cuadrada. (Storni, 1964, p. 34)

\subsection{Fervor de Buenos Aires, Jorge Luis Borges}

Fue publicado en 1923 y escrito bajo el influjo del ultraísmo literario, luego de su regreso a Argentina tras los años vividos en Europa. Se trata de su primer libro de poesía y en él se anticipa con nitidez su obra futura. En sus pinas ya aparecen las metáforas clásicas, la adjetivación asombrosa y los planteos metafísicos.

El tema central son los suburbios de la ciudad y sus personajes en el deslinde donde el barrio se desdibuja en el campo. Esa tensión entre lo particular y lo universal funda en nuestras letras un nuevo modo de observar la realidad cotidiana, una exquisita poética de lo inestable y de la nostalgia por lo perdido. La ciudad, elección de un tema moderno que contrasta con 
la retórica del paisaje campestre, tiene el doble interés de ser relativamente original con respecto a la tradición poética argentina, y de vincularse con la modernidad poética europea y norteamericana (Baudelaire, Whitman, y Juan Ramón Jiménez o el Poeta en Nueva York de Lorca). Buenos Aires no había conseguido aún la inmortalidad poética, a diferencia de París o de Londres. El arrabal porteño es el Buenos Aires querido de la infancia ya lejana del autor, pero también el que daba pie a una incipiente mitología criollista, en especial gracias a Evaristo Carriego y al tango, una mitología en que Borges encontraba un «vocabulario» en el que potencialmente podían expresarse emociones íntimas.

Para los arquitectos del momento «el más grave defecto de nuestra ciudad [...] es su gran extensión». Así lo manifiesta Víctor Jaeschké, difusor de la arquitectura pintoresquista, en «carta abierta» al intendente Bullrich en 1898 (Gorelik, 2004). Borges encuentra en el suburbio valores para nutrir su imaginería literaria. Allí, en estas calles empedradas, desde donde se divisa el horizonte, el espacio público articula pasado y presente.

Arrabal

El arrabal es el reflejo de nuestro tedio.

Mis pasos claudicaron

cuando iban a pisar el horizonte

y quedé entre las casas,

cuadriculadas en manzanas

diferentes e iguales

como si fueran todas ellas

monótonos recuerdos repetidos

de una sola manzana.

El pastito precario

desesperadamente esperanzado, salpicaba las piedras de la calle

y divisé en la hondura

los naipes de colores del poniente

y sentí Buenos Aires.

Esta ciudad que yo creí mi pasado

es mi porvenir, mi presente;

los años que he vivido en Europa son ilusorios,

yo estaba siempre (y estaré) en Buenos Aires. (Borges, 2007, p. 50) 


\subsection{Adán Buenosayres, Leopoldo Marechal}

Es una novela de Leopoldo Marechal publicada en 1948, pero que comienza a escribir en 1929. Salvo por el comentario elogioso de Julio Cortázar (que intenta, al mismo tiempo, una crítica rigurosa de la obra) y la opinión favorable de algunos pocos escritores, la novela de Marechal pasa inadvertida en su tiempo. La crítica pudo verse quizás superada por la aventura formal que proponía la novela, por sus procedimientos narrativos y de lenguaje que luego resultarían habituales en la novela latinoamericana. Sean cuales fueren las causas de este primer desencuentro, lo cierto es que más tarde las nuevas promociones reconocen en Adán Buenosayres a una obra precursora.

La novela, se organiza en siete libros. Los cinco primeros narran la aventura de Adán Buenosayres durante los días jueves 28, viernes 29 y sábado 30 de abril en un indeterminado año de la década del 20. El libro sexto («El cuaderno de tapas azules») es una autobiografía del protagonista de la historia, y el séptimo («Viaje»), un descenso simbólico a los infiernos. Las referencias homéricas y dantescas se unen a las alusiones bíblicas; el viaje, el compañero de aventuras o quien oficia de guía en estos universos desconocidos. El destino de Adán Buenosayres adquiere entonces un carácter mítico. Su principal centro de interés está en el mismo protagonista, en su viaje por el cielo y el infierno de su ciudad.

Marechal nos revela el carácter caótico y mágico de la ciudad y del barrio. El espíritu del lugar y la evidencia del tiempo se encarnan en su obra, a través de la imagen poética. Estas imágenes surgen de un hombre captado en su actualidad, arraigándose en la comunidad, ayudando a nombrar su universo y a despertar imágenes borradas. Estas imágenes nos permiten una visión diferente de los espacios, donde los valores imaginados son los dominantes.

La relación directa entre el autor y el paisaje es captada y encarnada en estos espacios imaginados. Nos revelan lo que percibe y comprende del mundo físico que lo rodea, ya sea desde su mirada individual o compartida por todo un grupo cultural.

Nos propone el autor en su Adán Buenosayres un viaje a través de los barrios, de ellos, habitándolos. Nos involucra como lectores y como personajes de su obra en la celebración del camino. A lo largo de Adán Buenosayres 
nos devela su simbología, la estructura física y metafísica del territorio de la ciudad:

Las doce campanadas eran doce mochuelos: Alguien abrió la puerta de la torre, y huyeron.

Medianoche: soledad y vacío. Sólo yo solo en la corteza de un mundo que gira huyendo, que huye girando, «viejo trompo sin niños». [...] Adán se detiene, bajo la lluvia, en la esquina de Gurruchaga y Triunvirato. Desde allí, todavía indeciso, contempla el ámbito fantasmal de la calle Gurruchaga, un túnel abierto en la misma pulpa de la noche y alargado entre dos filas de paraísos tiritantes que, con sus argollas de metal a los pies, fingen dos hileras de galeotes en marcha rumbo al invierno. Fosforescente como el ojo de un gato, el reloj de San Bernardo atisba desde su torre: no queda ya en el aire ni una vibración de la última campanada, y el silencio fluye ahora de lo alto, sangre de campanas muertas. Inesperadamente, una ráfaga traidora sacude los árboles, que se ponen a lloriquear como niños: Adán recibe un puñado de lluvia en la cara y se tambalea entre un diluvio de hojas que caen y se arrastran con un rumor de papeles viejos, mientras que los faroles colgantes ejecutan arriba un loco bailoteo de ahorcados. Pasó la ráfaga: el silencio y la quietud se reconstruyen bajo el canturreo de la lluvia. Soledad y vacío, Adán entra la calle Gurruchaga.

-Puertas y ventanas herméticas, llaves echadas, pasadores corridos: así defienden su evasión por el sueño. La casa del que duerme toma precauciones de trinchera o de tumba. (Marechal, 2006, p. 204)

\section{De la calle al barrio}

El espacio público constituye la manifestación más esencial de la ciudad, es la base de la convivencia y el ámbito de representación de la colectividad. Lo público pasa por captación de la densidad (de actividades, personas, etc.) que se manifiestan en un espacio cualquiera y que lo convierten, por intensidad en público, abierto. Adrián Gorelik habla de la radical ambigüedad del concepto de espacio público que al mismo tiempo: «nombra lugares materiales y remite a esferas de la acción humana» (Gorelik, 2004, p. 331). Cumple el rol de mediar entre la sociedad y el Estado. 
La reestructuración del espacio urbano se lleva a cabo por la apropiación y la dotación de nuevos significados a los espacios disponibles (haciéndolos espacios de lo público), sean estos lugares triviales o resquicios, capaces de absorber actividades transitorias. Los ciudadanos son portadores del espacio público, afirma Habermas (1998).

El espacio público urbano es continente y al mismo tiempo contenido, territorio y símbolo, lugar y habla, materia y memoria. Es el lugar de los deseos, pero también el de las prácticas concretas, es por tanto un territorio cuya accesibilidad y vivencias son indispensables para la concreción de toda construcción social y de cualquier práctica democrática.

Miramos la categoría del espacio público a través de cuatro escritores contemporáneos. Ellos nos brindan cuatro fragmentos que describen desde la sensibilidad, las transformaciones en la ciudad, las voluntades políticas en cuanto a la configuración del territorio, la emergencia de una nueva sociedad. La literatura aporta contenidos que se cruzan con los conocimientos del espacio público que estudiamos desde el urbanismo y la arquitectura. Roberto Arlt es un detective del nuevo espacio público, nos descubre los indicios de lo que será. Alfonsina Storni, plasma el sentido de exclusión de las mujeres en las decisiones sobre el mismo. Jorge Luis Borges, a pesar de la nostalgia, valoriza las nuevas extensiones como el espacio del porvenir. Finalmente, Leopoldo Marechal nos induce a pensar otras proyecciones; la lectura de una ciudad del progreso y de una ciudad bárbara conviviendo en el mismo tiempo, o una ciudad mecánica y una ciudad vivida, donde la metrópolis puede ser resultado del proyecto de modernización - una ciudad en marcha-, frente al barrio como el lugar de pertenencia, de la comunidad, el lugar próximo, con el que nos identificamos y donde coinciden nuestras experiencias y nuestros afectos.

Si bien los escritores tratan en su literatura el tema de la calle y de la manzana - tradicionales y casi únicos elementos del urbanismo derivados de las leyes de Indias españolas - en sus distintas visiones trasunta sin embargo una misma conciencia de transformación urbana. Son los nuevos barrios los que se están definiendo y conformando, donde la calle y la manzana resultan vehículos de este crecimiento demográfico. 
Desde la literatura coincidimos en esas cuatro visiones diversas, complejas, opuestas pero a su vez de alguna manera complementándolas uno puede hacerse una idea del espacio urbano de Buenos Aires de la época. Esta forma de observar un momento de la ciudad a través de miradas contemporáneas que provienen de un campo extradisciplinar brindan compresión a su complejo fenómeno de transformaciones.

Desde la historia del urbanismo sabemos que en ese período Buenos Aires está creciendo frenéticamente, que los protagonistas de las grandes obras de infraestructura urbana son los ingenieros, y que los arquitectos están por ahora abocados solamente a la edilicia de gran escala.

El Estado planifica a su modo el crecimiento, estableciendo los límites de la ciudad, creando sus parques, siguiendo la tendencia y casi en simultáneo que otras grandes capitales, y extendiendo la cuadrícula preexistente. Las decisiones políticas y urbanísticas están principalmente basadas en lo formal y en lo pragmático de las conexiones. Instituciones como la Sociedad Central de Arquitectos también apoyan estas posturas.

Existen sin embargo arquitectos críticos y preocupados por esta vitalidad del barrio como espacio público diferencial. Fermín Bereterbide (1895-1979), también contemporáneo de nuestros escritores, presenta una nueva propuesta de urbanidad. Su proyecto para el Barrio Parque Los Andes tiene mucho que ver con algunos de los conceptos que aparecen en los textos literarios. El proyecto que fue resultado de un concurso realizado por la Municipalidad en 1924 (contemporáneamente a los textos de Storni, Borges y Arlt) que Bereterbide gana a los pocos años de recibirse de arquitecto. Se trata de un conjunto de viviendas colectivas donde la manzana tradicional se renueva en una reinterpretación de los Hoffs de Viena o los conjuntos habitacionales holandeses. No se trata de una reelaboración de las casas chorizo que rodean al conjunto, ni una reivindicación de sus patios, ni de la arquitectura vernácula de nuestra manzana. Los espacios comunes se articulan en un espacio fluido interno de gran calidad y en una escala intermedia entre los patios domésticos tradicionales y una plaza pública. El gran espacio público central del conjunto se integra visualmente con el verde del parque vecino, a través de una glorieta. Su mirada alternativa se orienta, no hacia el debate entre modernismo o academicismo sino hacia otras vanguardias intelectuales vigentes, como el 
higienismo médico y el socialismo utópico, en una operación que refiere a las elecciones de Arlt. Su arquitectura, humana en sus espacios y en su escala, se acerca a la sensibilidad de Storni y pareciera generar una nueva identidad barrial tal como la propone Marechal.

Aquello que en el blog Sembrar en el desierto se vislumbra como una intuición, se convierte aquí en una posible hipótesis. Una conclusión improbable pero a su vez posible, como las relaciones trazadas arbitrariamente en el sitio web, replanteadas aquí con cierto rigor histórico.

Este grupo de jóvenes escritores y nuestro arquitecto, caminan, habitan y reflexionan sobre la periferia y sus barrios, el nuevo espacio público que configura la ciudad de Buenos Aires en los años 20, sobre su tejido social diferente y diverso cultural y étnicamente. Aunque juntos no conformaban un movimiento cultural ni literario, ni todos tenían vínculos amistosos entre sí, o siquiera compartían ideas políticas, estos intelectuales convivieron intensamente en la misma ciudad y en el mismo tiempo histórico, observando con lucidez y sensibilidad las calles y el barrio, aportando desde diferentes perspectivas mayor espesor teórico a nuestras actuales reflexiones.

\section{Referencias}

ArLt, R. (2001). Aguafuertes porteñas. Buenos Aires: Losada.

BaChelard, G. (1965). La poética del espacio. México: Fondo de Cultura Económica.

Benjamin, W. (2005). Libro de los pasajes. Madrid: Akal.

Borges, J. L. (2007). Fervor de Buenos Aires. Buenos Aires: Emesé Editores.

Calvino, I. (2015). Las ciudades invisibles. Madrid: Siruela.

D'amico, A., Facio, S., y Cortazar, J. (1968). Buenos Aires Buenos Aires. Buenos Aires: Sudamericana.

Doberti, R. (2008). Espacialidades. Buenos Aires: Infinito.

Durrell, L. (2003). Justine, El cuarteto de Alejandría. Buenos Aires: EDHASA.

Eyras, I., \& Moisset, I. (2014). Sembrar en el desierto. Recuperado el 10 de septiembre de 2016 de https://sembrareneldesierto.wordpress.com/ 
GolobofF, M. (2002). «Roberto Arlt: la máquina literaria». Revista de Literaturas Modernas (32), 107-115.

GoRELIK, A. (2004). La grilla y el parque. Espacio público y cultura urbana en Buenos Aires 1887-1936. Buenos Aires: Universidad Nacional de Quilmes.

Grau, C. (1989). Borges y la arquitectura. Madrid: Cátedra.

Habermas, J. (1998). Facticidad y validez. Madrid: Trotta.

Makarius, S. (1963). Buenos Aires, mi ciudad. Buenos Aires: Eudeba.

Marechal, L. (2006). Adán Buenosayres. Barcelona: Seix Barral.

Meyer, E. (1988). Escribir es un modo de habitar, Entrevista a Jacques Derrida. Arquitectura Viva (1).

SAbugo, M. (2013). Del barrio al centro: imaginarios del habitar en las letras del tango. Buenos Aires: Café de las ciudades.

Sessa, A., y Mujica Lainez, M. (1977). Letra e imagen de Buenos Aires. Buenos Aires: Librería La ciudad.

Storni, A. (1964). El dulce daño. Sociedad Editora Latino Americana, 1964.

Szmetan, R. (enero/junio de 1999). «La situación social de las escritoras argentinas en las primeras décadas del siglo xx. Antecedentes». Letras (51), 115-130.

W Aisman, M. (junio de 1985). «La ciudad que nos contaron». Summarios (90). 